\title{
Escrita e leitura de diários na formação de professoras para escolas rurais em Minas Gerais (1948-1974)'
}

\author{
Mônica Yumi Jinzenjil" \\ Iza Rodrigues da Luz" \\ Regina Helena de Freitas Campos"
}

\section{Resumo}

Este trabalho busca analisar os princípios norteadores da proposta de formação de professoras do Ginásio Normal Rural Oficial Sandoval Soares de Azevedo e alguns aspectos das práticas ali desenvolvidas, no período de 1948 a 1974 . Trata-se da primeira escola normal do estado de Minas Gerais voltada para a formação de professoras que atuariam no meio rural. Além dessa particularidade, a proposta diferenciada, marcada substancialmente pelos ideários desenvolvidos pela psicóloga e educadora Helena Antipoff e suas colaboradoras, dá destaque a essa instituição no cenário educativo mineiro e brasileiro. Observa-se, nessa análise, a ênfase dada ao que Antipoff chama de educação integral das normalistas, que alia a capacidade reflexiva e a dimensão socioafetiva aos valores democráticos e de bem-estar da coletividade, aspectos pouco discutidos nos trabalhos recentes voltados para o estudo dessa instituição. Trata-se de uma pesquisa documental desenvolvida no cruzamento de três tipos de fontes escritas: a legislação e documentos administrativos de caráter oficial/institucional; duas coletâneas que reúnem textos de Helena Antipoff de 1929 à década de 1970, publicadas em 2002 e 1992, respectivamente; seis diários de autoria das alunas da escola normal, em que relatam a rotina de atividades e expressam opiniões. Pode-se identificar, na proposta de educação integral desenvolvida na instituição, a adaptação dos princípios escolanovistas ao meio rural e a integração dos interesses e necessidades dos educandos aos princípios democráticos de autonomia e cooperação, visando ao bem-estar coletivo.

\section{Palavras-chave}

I- A pesquisa que deu origem a este artigo contou com o apoio financeiro da Fundação de Amparo à Pesquisa do Estado de Minas Gerais Educação integral - Escola Nova - Helena Antipoff - Educação rural - Diários.

(FAPEMIG).

II- Universidade Federal de Minas Gerais,

Belo Horizonte, MG, Brasil.

Contatos: monicayj@ufmg.br,

izarodriguesluz@gmail.com,

regihfc@terra.cm.br 


\title{
Writing and reading diaries in the education of teachers for the rural schools of Minas Gerais (1948-1974)'
}

\author{
Mônica Yumi Jinzenjil" \\ Iza Rodrigues da Luz" \\ Regina Helena de Freitas Campos"
}

\begin{abstract}
This work aims to analyze the main principles of the proposal of teacher education at Ginásio Normal Rural Oficial Sandoval Soares de Azevedo and some aspects of the practices developed there from 1948 to 1974. It was the first normal school in Minas Gerais state focused on the education of teachers for rural schools. Besides this particularity, its differentiated proposal, profoundly marked by ideals developed by the psychologist and educator Helena Antipoff and her collaborators, draws attention to this school in the educational scenario of Minas Gerais and Brazil. In this analysis, we can observe the emphasis given to what Antipoff called the comprehensive education of normal school students, connecting the development of reflection and socio-affective dimensions to the values of democracy and collective well-being, aspects hardly discussed in recent studies on this institution. This documental research has used three different written sources: legislation and official/institutional administrative documents; two collections of texts by Helena Antipoff from 1929 to the 1970s, published in 2002 and 1992, respectively; six diaries written by the normal school students, in which they reported their everyday activities and expressed their opinions. We can identify, in the proposal of comprehensive education developed in the institution, the adaptation of Escola Nova principles to the rural environment and the integration of interests and necessities of the students to the democratic principles of autonomy and cooperation, aiming at collective well-being.
\end{abstract}

\section{Keywords}

Comprehensive education - Escola Nova - Helena Antipoff - Rural education - Diaries.

I- The research for this article had the financial support of Fundação de Amparo à Pesquisa do Estado de Minas Gerais (FAPEMIG).

II- Universidade Federal de Minas Gerais,

Belo Horizonte, MG, Brazil.

Contact: monicayj@ufmg.br,

izarodriguesluz@gmail.com,

regihfc@terra.cm.br 


\section{Introdução}

Este trabalho tem como objetivo analisar os princípios norteadores da proposta de formação de professoras do Ginásio Normal Rural Oficial Sandoval Soares de Azevedo e alguns aspectos das práticas desenvolvidas no estabelecimento, no período de funcionamento da instituição, entre 1948 e 1974.

Trata-se da primeira escola normal do estado de Minas Gerais voltada para a formação de professoras que atuariam no meio rural. A instituição, além de ter essa particularidade, também tinha a proposta diferenciada, marcada substancialmente pelos ideários desenvolvidos pela psicóloga e educadora Helena Antipoff (1892-1974), motivos que destacaram a escola no cenário educativo mineiro e brasileiro. Observa-se em especial, nessa análise, a ênfase dada ao que a educadora e psicóloga chama de educação integral das normalistas, que alia a capacidade reflexiva e a dimensão socioafetiva aos valores democráticos e de bem-estar da coletividade, aspectos pouco discutidos nos trabalhos recentes voltados para o estudo dessa instituição ${ }^{1}$.

Trata-se de um tema de relevância especial para refletirmos a respeito da formação de professores/as, pois as demandas sociais colocadas hoje às escolas evidenciam a sua importância na formação de crianças e de adolescentes críticos para o exercício da cidadania. Para tanto, o princípio de educação integral se mostra um elemento relevante para questionar a função das instituições escolares como contextos restritos à transmissão de conteúdos técnicos e científicos que reforçam um olhar sobre o sujeito fragmentado.

Ao longo dos vinte e cinco anos de existência do Ginásio Normal Rural, foi produzido um volume grande de textos - de autoria de Helena Antipoff, sua fundadora, mas também de professores/as, diretores/as e estudantes -, assim como imagens e objetos.

1- Ver Andrade (2006), Pinto (2007), Pincer (2008) e Pinho (2009).
Neste trabalho, priorizamos as fontes escritas (impressas e manuscritas), buscando cotejar as propostas pedagógicas e as práticas delas resultantes, num movimento de análise das permanências, rupturas e de possíveis tensões.

A prolífica produção de Antipoff foi compilada e organizada em duas publicações que reúnem tanto artigos científicos originalmente publicados em revistas especializadas, quanto reflexões teóricas a respeito da educação, documentos de caráter pedagógico-administrativo (propostas de regulamentos, balanços avaliativos dos estabelecimentos), discursos em homenagem às formandas e outros. São escritos que datam da época de sua chegada ao Brasil, 1929, até a década de 1970. A primeira publicação, composta por quatro volumes intitulados Coletânea das obras escritas de Helena Antipoff, de 1992, possui um volume dedicado à educação rural. A coletânea de 2002, Helena Antipoff - Textos escolhidos, possui artigos de caráter científico e abrange variadas temáticas em psicologia e educação, incluindo a educação rural. Esses textos compilados formam um conjunto heterogêneo quanto à origem, ao direcionamento e aos objetivos, permitindo ao leitor um panorama de temas trabalhados pela educadora em diferentes períodos. Sabemos, por consequência, que tais fontes não esgotam as temáticas às quais se referem e nem possuem uma possível coerência ou linearidade entre si, efeitos que podem ser sugeridos pelo formato em que se apresentam.

A legislação e os documentos administrativos de caráter oficial/institucional possibilitaram compreender as prescrições curriculares, os programas dos cursos, os fluxos de docentes e discentes, caracterizando um ambiente escolar idealizado. Esses documentos estão localizados principalmente no acervo do Centro de Documentação e Pesquisa Helena Antipoff (CDPHA), situado na Universidade Federal de Minas Gerais, e no acervo do Memorial, localizado na Fundação Helena Antipoff, em Ibirité, Minas Gerais.

Foram analisados também documentos de autoria das alunas, denominados de diários. 
Trata-se do relato diário dos acontecimentos, que ficavam sob a responsabilidade das normalistas, num sistema de rodízio. Esses diários eram lidos em público durante o jantar e corrigidos quanto ao aspecto gramatical por algum professor. Além disso, eram avaliados quanto à exatidão e à extensão da descrição das atividades realizadas. Dessa forma, não se constituem em documentos pessoais das alunas, mas faziam parte da prática pedagógica desenvolvida na escola normal, sobre a qual discutiremos adiante. Os diários foram escritos ao longo dos 25 anos de funcionamento da instituição, estando reunidos em cadernos.

Dos 126 cadernos de diários encontrados no acervo do Memorial Helena Antipoff, foram utilizados, para análise, seis cadernos que continham os primeiros diários dos anos de 1950, 1955, 1960, 1965, 1970 e 1974, com a descrição de 141 dias. Os diários analisados foram escritos em cadernos pequenos (com $24 \mathrm{~cm}$ de altura e $17,7 \mathrm{~cm}$ de largura), do tipo brochura, grampeados e com capa dura, que possuíam em média 57 folhas. Somente no ano de 1974 foi utilizado um caderno grande (com $34 \mathrm{~cm}$ de altura e $23,9 \mathrm{~cm}$ de largura), contendo duzentas folhas. 0 relato de cada dia ocupava em média de quatro a oito páginas, a depender do suporte.

\section{Helena Antipoff e a educação rural no contexto das reformas educacionais do início do século XX}

A denominação escola rural foi criada no Brasil em fins do século XIX. As escolas rurais, localizadas em geral nas propriedades rurais, foram, desde então, caracterizadas, pelos discursos oficiais do período, pela precariedade no aspecto material e humano (MUSIAL, 2011). Na década de 1920, iniciativas governamentais como o ruralismo pedagógico buscaram desenvolver as escolas rurais por meio de estratégias educacionais que valorizavam a cultura do campo, incentivando, assim, a permanência e a fixação das populações rurais e contendo o fluxo migratório para os grandes centros ${ }^{2}$. Essas políticas foram sendo desenvolvidas nas décadas seguintes, sendo marcadas pela descontinuidade e alternância de responsabilidades entre a União, os estados e municípios, o que acarretava a supressão de escolas, a ausência de fiscalização e o prejuízo no desenvolvimento e consolidação desses estabelecimentos (COELHO, 2009; MALHEIROS, 2009; PINHO, 2009).

Correspondendo a esse cenário, em 1950, apenas $26 \%$ da população residente no meio rural em Minas Gerais sabia ler e escrever (IBGE, 1950). Quanto à realidade dos profissionais que atuavam nesses estabelecimentos, em 1948, dos 6.621 professores primários de escolas rurais em exercício, apenas 468, ou seja, 7,52\%, eram normalistas, fato que contribuiu para a centralidade dada ao investimento na qualificação do professorado do meio rural pelo governo mineiro nessa época (PINHO, 2009, p. 54).

A reforma educacional de 1927-28, conhecida como Reforma Francisco Campos Mário Casassanta, já trazia a preocupação com a qualificação dos professores do meio rural $^{3}$. Inspirada nos ideais escolanovistas, essa reforma propunha a renovação da escola como meio de reconstruir e modernizar a sociedade. 0 professor ganharia centralidade nesse projeto, como agente responsável pela qualidade da educação. Nesse cenário, em 1929, a convite do governo mineiro, Helena Antipoff chega a Belo Horizonte, inicialmente para dirigir o Laboratório de psicologia da escola de Aperfeiçoamento de Professores de Minas Gerais e colaborar na implantação da reforma educacional de 1927-28.

Nascida na Rússia, em 1892, e tendo feito sua formação em Psicologia e Educação em Paris, no Laboratório Binet-Simon (1911) e em

\footnotetext{
2- Sobretudo a partir de meados do século XX, o êxodo rural marcou a vida das populações rurais, motivado por precárias condições de vida, predomínio das grandes propriedades e mecanização da agricultura. Isso promoveu necessidade de intervenção por parte do governo (MELLO; NOVAIS, 1998).

3- Considerando que, em 1920, 75\% da população do estado residia no meio rural, tal preocupação se fazia premente.
} 
Genebra, no Instituto Jean-Jacques Rousseau (1912-1915), Antipoff participou de alguns dos primeiros ensaios de aplicação da psicologia científica à educação na Europa ${ }^{4}$.

No Brasil, seu trabalho como pesquisadora e psicóloga seguiu diversas vertentes. Nos anos de 1930, no Laboratório de Psicologia, realizou extenso programa de pesquisa a respeito do desenvolvimento mental das crianças mineiras em idade escolar, padronizando para a população local testes de inteligência e de personalidade. Em 1932, liderou a criação da Sociedade Pestalozzi de Minas Gerais, a partir da qual iniciou sólido trabalho de assistência a crianças excepcionais e abandonadas. Nos anos de 1940, o trabalho da Sociedade Pestalozzi se ampliou, através da criação da Fazenda do Rosário, escola modelo para a educação de excepcionais, que depois incluiu também a preparação de professores rurais e a formação de psicólogos, com a vinda de especialistas estrangeiros para cursos de especialização (ANTIPOFF, 1975; CAMPOS; ASSIS; LOURENÇO, 2002).

Localizada a 28 quilômetros de Belo Horizonte, na zona rural do distrito de Ibirité, município de Betim, Minas Gerais, a Fazenda do Rosário foi adquirida em 1939 para o estabelecimento de várias ações relacionadas à Sociedade Pestalozzi de Minas Gerais. Segundo Antipoff, a localidade possuía as características ideais para isso, pelo aspecto bucólico característico do campo e, ao mesmo tempo, o fácil acesso aos centros urbanos (CDPHA, 1992, p. 72; PINHO, 2009, p. 57).

Em menos de dez anos, as atividades ampliaram-se significativamente ${ }^{5}$ e o complexo da Fazenda do Rosário se tornou referência

4- Entre 1916 e 1924, voltou à Rússia, participou de trabalhos de exame e planejamento da reeducação de crianças abandonadas no período pósrevolucionário. Nessa ocasião, informou-se sobre as novas correntes da psicologia soviética. De volta à Suíça, em 1925, tornou-se assistente de Edouard Claparède no Institut Rousseau.

5- Durante o período de 1940 a 1970, a Fazenda do Rosário agregou outras instituições: escola primária, curso de aperfeiçoamento para professores rurais, curso normal regional, seminários de estudos rurais, cursos de férias para professores rurais etc. na elaboração de políticas voltadas para o desenvolvimento da educação no meio rural.

0 Curso Normal Regional Sandoval Soares de Azevedo foi criado pelo governo do estado de Minas Gerais pela Lei n. ${ }^{\circ} 291$, de 24 de novembro de 1948, e regulamentado com a Lei . $^{\circ}$ 842, de 26 de dezembro de 1951, sendo Helena Antipoff designada para dirigi-lo. Foi instalado no dia 19 de agosto de 1949, na sede da Fazenda do Rosário, com manutenção assegurada pelo governo do Estado e como instituição integrante do Sistema Estadual de Ensino. Em 1961, transformou-se em Ginásio Normal e, posteriormente, conforme Decreto n. ${ }^{\circ}$ 6.879, de 13 de março de 1963, e resolução $n^{\circ} 32 / 65$ do Conselho Estadual de Educação, recebeu a designação de Ginásio Normal Rural Oficial Sandoval Soares de Azevedo ${ }^{6}$.

0 Ginásio Normal tinha como finalidade ministrar o primeiro ciclo do ensino normal e formar regentes de ensino primário para a zona rural. 0 curso funcionava em regime de internato em tempo integral, com quatro anos de duração e atendendo o público feminino. As candidatas deveriam ter entre 13 e 25 anos de idade e eram submetidas a exame de admissão que envolvia os conteúdos do curso primário: português, matemática, geografia, história do Brasil e ciências naturais. Eram consideradas aprovadas as candidatas que obtivessem nota igual ou superior a cinco em português, e média geral de pelo menos cinco nas demais disciplinas. A essa média final era acrescentado um ponto para a candidata proveniente de zona rural e um ponto a candidatas que comprovassem o exercício de magistério, critérios finais que indicam a prioridade dada à formação e qualificação das populações rurais e atuantes na docência.

Essa estrutura permaneceu até a promulgação da Lei de Diretrizes e Bases da Educação, Lei n. ${ }^{\circ} 5.692$ de 11 de agosto de 1971,

6-As instalações definitivas da escola localizaram-se em uma propriedade adquirida em Ibirité pelo Governo do Estado. A área de $317.284 \mathrm{~m}^{2}$ teve suas escrituras lavradas em 24/09/1951 e 21/08/1960, no Cartório do $4^{\circ}$ Ofício, Belo Horizonte, e registradas no Cartório de Imóveis, em Betim, MG. 
que proibiu a formação do professor somente no nível do $1^{\circ}$ grau. A partir desse ano, não houve mais a formação de novas turmas para o curso normal rural que teve suas atividades encerradas no ano de 1974, com a formatura da turma que iniciou o curso no ano de 1971.

\section{Dos regulamentos aos diários: diálogos}

É possível identificar que, para Helena Antipoff, a escrita dos diários ganhava centralidade dentro do conjunto das práticas pedagógicas desenvolvidas no Ginásio Normal por dois aspectos fundamentais: um deles se refere ao desenvolvimento de habilidades psicológicas que a prática pode proporcionar, pois, em suas palavras, a escrita dos diários:

[...] costumam os jovens a prestar atenção à quantidade de fatos, selecionando-os na sua maior ou menor importância, a meditar sobre as relações que ligam uns aos outros, facilitando assim a formação de bons hábitos de observação, de testemunho, de pensamento lógico disciplinado. (ANTIPOFF, 1949/1992, p. 66).

Por outro lado, Antipoff credita aos registros diários o espaço de guarda da memória e da história das instituições, de suas práticas, motivo pelo qual defende que estes devessem ser acumulados e conservados, posto serem, segundo ela, “documentação real e autêntica para sua História - e, consequentemente, para o julgamento objetivo de seu valor como órgãos de formação de mestras rurais de Minas" (ANTIPOFF, [1958] 1992, p. 127).

Em 1948, no início das atividades do Ginásio Normal, podemos observar o otimismo de Antipoff em relação a esse instrumento. No texto "0 diário do curso rural está melhorando...", em que avalia o amadurecimento na escrita das normalistas, que já não mais se limitavam a reproduzir o cronograma de atividades do dia, mas produziam narrativas cada vez mais "plásticas e pitorescas" em que o espírito "já procura penetrar o sentido do percebido, e cada narrador começa a revelar seu próprio jeito de dizer as coisas" (ANTIPOFF, [1948], 1992, p. 47). Nesse momento, Antipoff demonstrava estar mais preocupada com o conteúdo que com a forma, na medida em que aponta que os "erros gramaticais e as frases maltalhadas", efetivamente presentes, deveriam ser secundarizados. Em momento posterior, ao ler os diários do curso de treinamento, em 1953, revela seu desapontamento, sobretudo com a forma:

A leitura dos diários do $5^{\circ}$ curso de
treinamento revela o nível cultural do
corpo discente bem baixo, de modo geral.
O português é deficiente e deve-se dar uma
especial atenção às aulas da língua pátria,
que devem ser muito intensas, para que
nos meses restantes as professora-alunas
possam recuperar as falhas. (ANTIPOFF,
[1953] 1992, p. 96).

Essa tensão entre conteúdo e forma e entre o caráter descritivo ou reflexivo dos registros parece persistir ao longo de todo o período do curso, havendo mesmo diferentes significados atribuídos a esse instrumento formativo, que revelam distintos modos de dedicação a essa escrita. No último ano da última turma do Ginásio Normal:

[...] à hora do jantar, o diretor chamou a atenção sobre o diário. E disse que não queria lista de horário. A diarista, não aceitando as reclamações do mesmo, respondeu, colocando-o nervoso e fazendo com que este se levantasse e rasgasse o diário. (DIÁRIO DE..., 1974).

Já outras práticas, na verdade desdobramentos dessa proposta pedagógica nas escolas rurais, são recebidas com satisfação por Antipoff, que anuncia às formandas de 1958: 
[...] vejo o Diário, com satisfação inefável, espalhando-se pelas escolinhas rurais, através das páginas de tocante candura infantil. A leitura desses diários, que nos mandam as mestras, nos enche de alegria e de gratidão para todas as ex-alunas dos cursos rurais de professores que, o introduzindo em suas classes, deixamnos assim penetrar nos seus novos ambientes escolares, e, de longe, assistir às atividades que ali se desenrolam, crivadas de dificuldades e privações, mas cheias, muitas delas, de verdadeiro heroísmo, onde a iniciativa e a boa cooperação tudo resolvem. (ANTIPOFF, [1958] 1992, p. 126).

Antipoff declara explicitamente às formandas sua expectativa de que a prática da escrita do diário também seja mantida pelas mesmas nas suas respectivas escolas, para que os pequenos aprendam desde cedo a observar com atenção, a avaliar e a julgar, contando com as mestras para auxiliar no registro. Ao mesmo tempo, segundo ela, esse instrumento é de grande valia para que a mestra compreenda melhor o estudante e suas especificidades, para que possa desenvolver sua prática docente de acordo com as necessidades apresentadas.

Os diários escolares, referidos também como cadernos de rodízio (HÉBRARD, 2001; VINÃO, 2008), são instrumentos de uso pedagógico exemplares entre aqueles desenvolvidos pelas pedagogias ativas. Tendo como suporte os cadernos, passaram a fazer parte da cultura material dos estabelecimentos escolares na era moderna, mais especificamente a partir de meados do século XIX. Tem-se notícia da introdução dos cadernos de rodízio nas escolas francesas em 1895, passando logo a fazer parte da rotina das escolas de outros países europeus (VINÃO, 2008).

Os diários analisados possibilitam o acesso às práticas escolares, apresentando uma série de vantagens em relação a outros tipos de fonte de cunho oficial, como a legislação e os livros e manuais utilizados nas aulas. Sua leitura pública, realizada antes do registro definitivo, contribui para a legitimação dos conteúdos, que passam a ser coletivamente compartilhados. A análise não possibilita, no entanto, a reconstrução do currículo real ou do cotidiano vivido e sentido, e não podemos considerar os relatos como neutros: a escrita resulta de atividade de criação pelas mãos das alunas, mas é produto de uma prática escolar, estando submetida a um conjunto de normas, objetivos e significados pré-determinados e que muitas vezes escapam ao sujeito que escreve (GVIRTZ, 2008).

Ao entrarmos nesse cotidiano apresentado pelas alunas, chama-nos a atenção o fato de a maioria dos serviços de manutenção da Escola Normal Rural ser feita por elas: arrumação dos dormitórios, limpeza do refeitório, limpeza da cozinha, manutenção da horta, do pomar, cuidado com pequenos animais. Havia empregados somente para a execução de trabalhos considerados mais pesados e para a preparação das refeições. A organização da escala de trabalho das alunas era feita quinzenalmente num sistema de rodízio, de modo que todas as alunas realizavam todos os tipos de tarefas. Além das atividades de manutenção da escola e de seus pertences (roupas e calçados), as alunas cumpriam o cronograma diário das aulas das disciplinas regulares do curso normal. Eram previstos horários para repouso e estudos individuais, além do horário livre. Desse modo, um dia típico era organizado do seguinte modo (com pequenas variações nos horários):

- 6h - Acordar, fazer a higiene pessoal e organizar o dormitório;

- 7h - Café da manhã;

- 7h30 - Práticas curriculares no campo: horta, jardim, cuidado com os animais e limpeza da área externa do prédio;

- 9h20 - Banho;

- 10h - Horário de estudo individual ou de lavação de roupas (cada dia da semana, uma turma lavava suas roupas) e da limpeza geral do refeitório, das salas de aula e dos dormitórios; 
- 11h - Almoço;

- 11 h30 - Repouso ou limpeza dos banheiros (rodízio na ala, cada semana uma turma era escalada);

- $12 \mathrm{~h} 25$ às $17 \mathrm{~h} 05$ - Aulas teóricas;

- 17h30 - Horário livre;

- $18 \mathrm{~h}$ - Jantar;

- 18 h30 às $19 \mathrm{~h}$ - Horário de lazer;

- 19h15 - 21h - Horário de oração coletiva (rezar o terço - facultativo) e de estudos com acompanhamento de uma professora;

- 21h00 - Lanche (chá com torradas ou biscoitos) e repouso.

Essa rotina geral sofreu poucas alterações ao longo dos anos. A responsabilidade pelo cumprimento das escalas de trabalho e o cumprimento dos horários era de cada aluna, sendo supervisionadas por funcionários, professores ou por colegas. 0 conjunto das atividades atende aos três pilares mínimos para as Escolas Novas, elaborados por Adolphe Ferrière - fundador do Bureau Internacional des Écoles Nouvelles em Genebra, que tinha como objetivo reunir informações e promover o intercâmbio de ideias e propostas entre os educadores envolvidos com a renovação da educação em diversos países (CLAPARÉDE, 1926) -, quais sejam: ser localizada no campo, desenvolver a educação pela experiência e desenvolver trabalhos manuais para complementar a ação pedagógica. A esses princípios acrescenta-se a preocupação com a educação para a cidadania e para a democracia, presente nos escritos e no modo como as atividades coletivas eram desenvolvidas no Ginásio Normal. Esses elementos caracterizariam a educação integral proposta por Antipoff.

\section{O exercício da cooperação no desenvolvimento de trabalhos coletivos: a aprendizagem pela experiência}

A participação das alunas normalistas em todas as atividades relativas à organização e manutenção do espaço físico da escola, ao auxílio no preparo e distribuição das refeições e aos cuidados com objetos pessoais está sendo compreendida como um modo de implementar a cooperação como um príncipio pedagógico, visto que o bem-estar de todos dependia do cumprimento das responsabilidades individuais. Essa perspectiva, inspirada no método da experimentação natural, de Lazursky ${ }^{7}$, acaba por privilegiar, ao invés da competição, comum nos estabelecimentos escolares, a cooperação, ou seja, a aprendizagem em um ambiente de ajuda mútua e de tomadas de decisões coletivas (CAMPOS; ASSIS; LOURENÇO, 2002, p. 28). Fica explícita também a influência dos princípios escolanovistas defendidos por Edouard Claparède em Genebra: buscar meios para fazer florescer a democracia, prevalecendo o respeito à liberdade e à autonomia.

Antipoff ([1945] 2002) explicita que a escola deveria funcionar numa atmosfera de franqueza e de confiança mútua, de modo que se pudessem identificar as pessoas que não estivessem contribuindo para o bem-estar da coletividade. Desse modo, o exercício da democracia no interior das escolas era tido como fundamental, sendo a formação das atitudes dos alunos considerada como o principal objetivo da escola. Na citação abaixo, fica evidente que a formação de atitudes cooperativas devia ser trabalhada de maneira prática, através de vivências e de experiências que possibilitassem aos alunos realizar o máximo de suas capacidades em benefício de todos:

A democracia, psicologicamente falando, é a atmosfera que, na vida de uma coletividade organizada, permite a cada um realizar o máximo de suas capacidades em benefício de todos. É, sem dúvida nenhuma, problema psicológico, que se resolverá com maior possibilidade de êxito quando nas escolas de todos os graus, for considerada a formação das

7- Alexander Lazursky (1874-1917) foi psiquiatra e psicólogo russo, estudioso da personalidade. Crítico dos testes psicológicos padronizados, propôs o método da experimentação natural para identificar características psicológicas através da observação dos sujeitos em atividade em ambientes naturais. 
atitudes das novas gerações; quando as escolas, desde o jardim da infância até a universidade, compreenderem que a democracia é regime de governo que se realizará com possível êxito quando a coletividade estiver apta a discriminar nos seus membros as qualidades necessárias aos chefes e dirigentes e praticar as virtudes do regime de responsabilidade e de lealdade autêntica.

Para garantir um bom regime democrático na sociedade adulta, a escola tem obrigação de exercitá-la ampla e sistematicamente no seu seio, acostumando desde cedo a criança à prática cotidiana de atitudes democráticas. (ANTIPOFF, [1945] 2002, p. 257-258).

Além dos trabalhos acima mencionados, a vivência em trabalhos práticos por meio da participação nos clubes, pequenas agremiações formadas pelas estudantes e caracterizadas pela realização de atividades coletivas em torno de algum tema de interesse comum, é outro ponto importante na organização da proposta pedagógica da instituição. Trata-se de um tipo de atividade diferenciada que promovia a difusão dos valores democráticos a partir da organização de diretorias eleitas. Nos relatos aparecem: clube agrícola, clube da leitura, clube esportivo, clube pedagógico, clube social e cooperativa (esta, uma loja em que se vendiam materiais escolares de consumo das próprias estudantes e que funcionava sob a administração das mesmas) ${ }^{8}$. As atividades de planejamento, organização e execução relativas aos clubes possibilitavam às alunas o exercício de diversas funções que exigiam responsabilidade, autonomia, capacidade de julgamento e iniciativa, características e atitudes que deveriam constituir, segundo Antipoff, uma formação integral. Desse modo, podiam vivenciar relações de poder e hierarquia, exercitar as capacidades argumentativas, enfim, vivenciar experiências diversificadas que identificamos como uma forma auxiliar no desenvolvimento das atitudes de cooperação e autonomia.

Outro aspecto a ser pontuado é que esses trabalhos não diminuíam a carga horária das disciplinas regulares, visto que a escola também primava pela difusão do conhecimento científico através das aulas teóricas e práticas ministradas às alunas, bem como pelas demais atividades de estudo, como a realização de exercícios de leitura e escrita voltados para a fixação de conteúdos ou para a realização de trabalhos individuais e coletivos de avaliação. Observe-se o quadro I com as disciplinas constantes do currículo e o período em que aparecem registradas nos diários.

Quadro 1 - Disciplinas do curso normal registradas na amostra dos diários analisados

\begin{tabular}{|c|c|c|c|c|c|c|}
\hline Disciplinas/ano & 1950 & 1955 & 1960 & 1965 & 1970 & 1974 \\
\hline \multicolumn{7}{|c|}{ Atividades agrícolas (Agropecuária) } \\
\hline \multicolumn{7}{|l|}{ Ciências (Biologia) } \\
\hline \multicolumn{7}{|l|}{ Economia doméstica } \\
\hline \multicolumn{7}{|l|}{ Educação física } \\
\hline \multicolumn{7}{|l|}{ Geografia } \\
\hline \multicolumn{7}{|l|}{ História } \\
\hline \multicolumn{7}{|l|}{ Português } \\
\hline \multicolumn{7}{|l|}{ Matemática } \\
\hline \multicolumn{7}{|l|}{ Religião } \\
\hline \multicolumn{7}{|l|}{ Trabalhos manuais } \\
\hline \multicolumn{7}{|l|}{ Música/canto } \\
\hline \multicolumn{7}{|l|}{ Psicologia } \\
\hline \multicolumn{7}{|l|}{ Biblioteca } \\
\hline \multicolumn{7}{|l|}{ Francês } \\
\hline \multicolumn{7}{|l|}{ Didática } \\
\hline Orientação religiosa & & & & & & \\
\hline
\end{tabular}

Fonte: Diários das normalistas dos anos de 1950,1955, 1960, 1965, 1970 e 1974.

8- Para maiores detalhes sobre os Clubes, ver Pinto (2007) e Pinho (2009). 
No cruzamento com a documentação oficial, verificamos que a escola cumpria os regulamentos oficiais que tratavam da organização dos cursos normais, e a inclusão ou a retirada de disciplinas seguiu essas regulamentações. Pudemos verificar, por exemplo, que a menor frequência da aparição das disciplinas de psicologia e didática (inicialmente prática de ensino), deve-se ao fato de que essas eram obrigatórias somente na terceira e quarta série. Quanto às aulas de idiomas estrangeiros (inglês e francês), constatamos que passaram a integrar o currículo no ano de 1963, o que justifica sua aparição somente nos relatos de 1965. A partir de 1966, ficou discriminada a dedicação de duas horas semanais, em todas as séries, para biblioteca. Entretanto, como os relatos da ida à biblioteca para fazer pesquisas aparecem desde 1950, acreditamos que essa já era uma prática desenvolvida na escola antes da sua formalização na grade curricular dos cursos normais.

Antipoff ([1930] 2002) criticava o sistema escolar pelo excesso de energia despendida na aquisição dos conhecimentos formais e pelo menosprezo das ações voltadas para o desenvolvimento da personalidade ${ }^{9}$. Esse pensamento parece subsidiar o modo de organização do cotidiano do ginásio normal, visto que o tempo das alunas era ocupado prioritariamente com os trabalhos de manutenção da própria escola, com as atividades práticas relacionadas ao meio rural e uma série de atividades artísticas e físicas que proporcionavam uma formação mais ampliada, tais como a apresentação de peças de teatro, escrita e apresentação de teatro de fantoches e de bonecos (além da confecção dos mesmos), trabalhos de cerâmica, bailado e apresentações de dança, canto, poesia, entre outros (diários).

0 princípio da educação integral, que tinha intencionalmente o objetivo de

9- Antipoff ([1934] 2002) compreende personalidade como uma condição que pode qualificar o sujeito adulto que tenha consciência do eu e certo grau de constância em relação às formas de comportamento intelectual, afetivo e social, sendo esse conjunto originado das relações sociais e referendado nos valores de determinada sociedade. ampliar a função das instituições escolares de modo a contemplar a formação do caráter/ personalidade dos educandos e a promover os ideais democráticos de responsabilidade e cooperação, parece ter ganhado concretude com esse modo de organização do cotidiano escolar. Essa organização foi possibilitada pelo regime de internato e pelas instalações da instituição em uma propriedade com ampla área verde que possibilitava a existência de hortas e criação de pequenos animais.

No processo de formação de atitudes cooperativas, solidárias e democráticas, são inevitáveis as discórdias e tensões, que acabam ganhando espaço nos relatos diários. Uma frase escrita em destaque no diário por uma das normalistas, "Devemos ser honestas e nunca parasitas das companheiras" (DIÁRIO DE..., 1960), sugere que nem sempre a cooperação e a harmonia se faziam presentes nas relações interpessoais. Semelhante a esse relato, no Diário de 1950, uma estudante relata o desconforto em emprestar seus objetos escolares, sugerindo, ao final, que cada uma tivesse seus próprios objetos de mais necessidade para que não tenham que pedir a outras colegas que também os estarão utilizando. Desentendimentos que resultam em agressões físicas também aparecem, embora com pequena incidência, não nos tendo sido possível verificar os procedimentos adotados ou resultantes desses incidentes.

A aprendizagem pela experiência, um dos pilares da Escola Nova, está no cerne da proposta pedagógica do Ginásio Normal. Essa proposta alinhava-se com os princípios do método intuitivo, baseado nas propostas pedagógicas de Froebel e Pestalozzi e que foi introduzido no Brasil, em fins do século XIX, nas escolas primárias. Afınado ao movimento escolanovista de crítica ao excessivo verbalismo na educação, tal método introduz a inovação no uso de objetos, materiais concretos e imagens, que façam com que a aprendizagem se torne ativa, baseada na observação e na ação (VALDEMARIN, 1998). No excerto abaixo, temos a ilustração de como Antipoff 
compreende o processo de aprendizagem por meio da experiência:

Ponto de partida - Necessidades. As dificuldades decorrentes do desejo de as satisfazer da maneira mais econômica possível estimularão toda espécie de operações mentais da inteligência e do uso e da utilização mais acertada, racional, dos meios que se acham à disposição, ou que devem ser ainda encontrados, trazidos no lugar e postos em ação.

Ter paciência em deixar os alunos descobrir bastante coisas e achar soluções individuais, originais, mesmo que incompletas. Ali, poderão apreciar o papel da ciência e o valor dos conhecimentos e da cultura. Muita coisa já tem resposta e melhor que aquela que os jovens se esforçam a pôr em prática. Mostrar, na realidade, quanto a ciência e seus serviços são mais econômicos que o do tateamento e da descoberta empírica, sem, no entanto, deixar secar a fonte da descoberta intuitiva, da experimentação e do conhecimento de "primeira mão", extraída ali mesmo, com meios próprios e recursos da inteligência e do esforço tenaz. (ANTIPOFF, [1962] 1992, p. 152).

Uma excursão realizada em 1952 para o Vale do Rio São Francisco, Minas Gerais, financiada pela Secretaria Estadual de Educação, teve repercussões que ganharam destaque entre as atividades usuais. Arlete Araújo, aluna que participou dessa atividade, redige uma nota publicada no periódico Juventude Ruralista, órgão do Curso Normal:

[...] não só conhecemos as cidades de Pirapora, S. Romão, São Francisco, Januária, Manga em Minais Gerais e Carinhanha e Bom Jesus da Lapa, na Bahia, mas além de conhecê-las, entramos em contacto direto com seus habitantes, observamos seus costumes, tomamos conhecimento de seus problemas, vivemos, embora por curto tempo, a vida dessa gente. Como se modificou para nós, êsse traçado quase sem importância, que no mapa, mostra-nos o percurso do rio São Francisco! Navegando durante muitos dias nas águas dêsse majestoso rio, sentimos quanto é real a sua existência, e quanto benefício pode um rio prestar ao homem. Agora compreendemos melhor como é útil estudar vendo e sentindo as cousas estudadas. Compreendemos que a geografia não é apenas conhecimento de relêvo, dos acidentes, etc. de um lugar, mas, muito mais ainda o conhecimento da vida da gente que o habita. (JUVENTUDE RURALISTA, 1952, p. 4, grifos nossos).

A reflexão refere-se não somente à aprendizagem, ao ganho de conhecimento, mas às mudanças nas próprias referências em relação ao aprender, "sentindo as coisas estudadas” e à problematização da geografia como disciplina. A experiência parece ter contribuído também para a produção de uma sensibilidade compreensiva em relação ao outro, seus costumes e aos problemas dessa população ribeirinha do cerrado norte-mineiro, o que está diretamente ligado à produção de atitudes cidadãs. Em relação à mesma excursão, Antipoff reflete especialmente a respeito de sua expectativa de que "Os interesses egocêntricos que até então reinavam no túmulo da vida juvenil deslocaram-se para fora, para o mundo, para o social" (ANTIPOFF, [1953] 1992, p. 101).

\section{Tempo livre, espontaneidade e privacidade}

No rígido cronograma diário das alunas, das quinze horas de atividades previstas, eram reservados trinta minutos para o tempo livre, geralmente ao final da tarde, das $17 \mathrm{~h} 30$ às 18h. As atividades descritas não variam muito ao longo dos anos, sendo que as atividades de lazer e as religiosas são as que mais estão presentes em todos os relatos, além 
da participação nos preparativos de eventos e a participação em eventos sazonais, práticas de voluntariado, atividades voltadas para o cuidado da saúde pessoal. Algumas normalistas relatam o uso do tempo livre para se envolver com atividades culturais como assistir a filmes, ouvir músicas, resgatar cantigas folclóricas, ensaiar e apresentar peças de teatro. Em ocasiões especiais, participavam de excursões para assistir, na cidade de Belo Horizonte, a espetáculos e apresentações musicais, teatrais e de dança.

Entretanto, não era apenas no tempo livre institucionalizado que as normalistas se expressavam de forma espontânea. Pequenas transgressões que se repetem indicam modos particulares de dar sentido à rotina e às regras: o barulho excessivo, especialmente após o toque de recolher, nos próprios dormitórios, foi citado com maior frequência; não acordar no horário; 0 esvaziamento no ato de hasteamento da bandeira nacional; pegar goiaba sem autorização. Esses são exemplos pontuais e/ou crônicos de eventos considerados como de indisciplina.

Alguns comportamentos de cunho moral também são destacados, como se maquiar durante as atividades escolares, utilizar linguajar não apropriado, ser "exibida" durante a missa, andar de mãos dadas com namorado em atividades comemorativas. 0 trote realizado por veteranas também é mencionado com alguma ressalva, pois envolvia o corte de cabelo das alunas novatas que as desobedeciam. Segundo os relatos, diante desses fatos, as atitudes institucionais invariavelmente caracterizavam-se pela repreensão e pela punição, muitas vezes vistas com indignação.

Os eventos de conversa nos dormitórios eram combatidos com a vigilância por parte de funcionárias; os comportamentos excessivos nas missas foram punidos com a suspensão na participação nas mesmas; quanto à ausência no hasteamento da bandeira, foi sugerido que a professora de história fizesse a chamada no referido local. Desse modo, ainda que os atos transgressores fossem relatados e lidos em público e as punições pudessem ser questionadas, indicando que havia na escola a possibilidade de se discutir essas questões, o modo como as normalistas relatam indica a relação de heteronomia com as regras e atitudes autoritárias institucionalizadas. No tratamento dado aos "excessos" dessas alunas, que em muitos casos são lesivos à coletividade, a proposta de formação integral, do ponto de vista dos princípios, parece manter a coerência, uma vez que autonomia não significa ausência de regras. No Ginásio Normal, a proposta parece primar pela promoção de autonomia possibilitada pelo cumprimento das regras, um aparente paradoxo que possivelmente não era tão facilmente compreendido pelas jovens, segundo esses tantos relatos.

Consideramos que o próprio ambiente do internato de jovens moças é propício para o afloramento e efusão de emoções que nem sempre possuem uma vazão apropriada. Em um sentido positivo, os relatos possibilitam entrever o ambiente afetivo, que parecia ser de bastante proximidade entre as educandas e as professoras e demais membros do corpo administrativo da escola. É comum, nos relatos, o destaque dado ao reestabelecimento da saúde de colegas e professoras que estiveram enfermas, bem como a referência ao adoecimento e à partida delas, a ausência da diretora por vários dias. A alegria em receber a visita de parentes ou de autoridades políticas e acadêmicas também movimenta o cenário da rotina repetitiva $\mathrm{e}$ merece destaque nos diários.

Um outro aspecto da escrita e da leitura pública dos diários que merece ser destacado é que sua prática parece tornar públicas até mesmo as experiências pessoais, de cunho privado, que não se desejaria compartilhar. Não se trata aqui dos sentimentos, opiniões que a relatora poderia omitir, caso preferisse, mas de situações que, embora em algum nível públicas, pudessem, com algum cuidado, serem mantidas num universo mais restrito de relações. 0 fato de ser vista de mãos dadas com um suposto namorado, de uma colega se desmanchar em 
lágrimas no refeitório ao ouvir a leitura de uma composição intitulada Minha mãe, por não possuir mãe, por exemplo, ou mesmo um adoecimento que se torna público podem gerar comentários excessivos, preocupações desnecessárias.

Ressaltamos, porém, que, ao longo do desenvolvimento de sua prática, o diário pode ter deixado de acolher os elementos de caráter privado. A partir de 1955, notamos a diminuição e, por vezes, a ausência, nos relatos, dos fatos agradáveis e desagradáveis, conforme orientação de Antipoff (ausentes nos anos de 1965, 1970 e 1974). Quesito que servia de orientação para que as alunas não apenas descrevessem o acontecido, mas exercitassem o olhar para o julgamento e a análise, começam a diminuir em frequência em relação ao período anterior e passam a ser substituídos, por exemplo, por fatos cômicos e charadas/ perguntas a respeito de conhecimentos gerais e brincadeiras (piadas), rimas ou notas. Aparecem também com bastante frequência citações de pensamentos de personalidades conhecidas ou de domínio popular.

É importante registrar também que, nesses últimos quatorze anos, os diários ficaram mais sintéticos. No único caderno do ano de 1974, a estrutura do diário é inteiramente diferente: aparecem descrições poéticas sobre a natureza, o dia, reflexões sobre a vida, a juventude, a religião; o cardápio das três refeições passa a ser relatado, assim como as professoras e pessoas presentes no refeitório; os fatos mais ligados à rotina da escola aparecem no final, juntamente com um pensamento. Se, na proposta inicial, os diários deveriam servir para promover nas alunas a capacidade de observação, síntese, julgamento e autoobservação, os objetivos pedagógicos do diário parecem ter sido modificados, resultando em maior autonomia das relatoras. Essa mudança pode ter ocorrido de modo não intencional; a continuidade da prática pode ter se esvaziado de sentido, adquirindo a forma que melhor convinha ou condizia com a relatora do dia.

\section{Considerações finais}

A escola civiliza o homem, oferecendo-Ihe ambientes novos e formando nele novos hábitos de vida em sociedade. A escola humaniza despertando a consciência e leva o homem a formas superiores de pensamento e de sentimentos. Como instrumento de nacionalização, a escola pública delineia a área física e moral de sua pátria e, unindo os indivíduos em grupos cada vez maiores, dita ao povo seus direitos e deveres de cidadãos. (Helena Antipoff)

As considerações acima sintetizam o pensamento de Helena Antipoff em relação ao papel da educação escolar para o desenvolvimento dos sujeitos educandos e ao mesmo tempo da sociedade, em consonância com o movimento de renovação educacional no qual se insere. Comunga desse movimento na crítica à escola clássica, intelectualista, cujo ensino se organiza em função da transmissão de conteúdos por meio da palavra e da memória. Além disso, compartilha da defesa de uma educação funcional, que respeite a liberdade e a individualidade do educando, fornecendo-lhe progressivamente os meios de adaptação à sociedade, vista como em fase de intensas transformações (CAMPOS; ASSIS; LOURENÇO, 2002).

Para Fernando de Azevedo, um dos principais líderes do movimento escolanovista no Brasil, a educação nova se organiza em duas tendências. De um lado, sob a influência da ciência psicológica, propõe maior liberdade para a criança, enfatiza a atividade livre e espontânea e a individualização do ensino. Por outro lado, considerando que é preciso que a criança também seja iniciada nos princípios da civilização que já existe, propõe organizar a escola como comunidade de vida, onde os princípios da solidariedade e da cooperação com o outro devem prevalecer (AZEVEDO, 1971, apud SAVIANI, 2007).

Helena Antipoff, por sua formação, reúne influências das duas tendências acima identificadas. Como aluna de Claparède e como uma das primeiras educadoras a atuar na Maison des Petits (escola experimental anexa ao Institut Rousseau), conheceu em profundidade 
as propostas da educação funcional e da escola ativa. Claparède propunha o que ele chamava de revolução copernicana, na educação, inspirada nas ideias de Rousseau: a escola deveria ser centrada no educando, em seus interesses e necessidades de desenvolvimento. Por outro lado, Antipoff conhecia muito bem as propostas de Dewey (a escola-comunidade) e de Freinet (a escola popular democrática). Mais que isso, compartilhava com Jean Piaget a ideia de que a educação deveria enfatizar o autogoverno e a cooperação, no sentido de educar sujeitos comprometidos e aptos a atuar em uma sociedade democrática (PARRATDAYAN; TRYPHON, 1998).

As heranças culturais russa e francesa, de valorização do campo, aparecem igualmente na base da proposta da Fazenda do Rosário. 0 campo é visto como lugar do atraso e da miséria, o que justifica a presença de professores e professoras comprometidas com uma educação que valorize para o camponês seu próprio meio, com o objetivo de conter o fluxo migratório para os grandes centros. Por outro lado, o campo também é tido como refúgio para o trabalhador que quer se afastar do tumulto da cidade e educar os filhos com saúde e felicidade (CAMPOS; LOURENÇO; ANTONINI, 2002, p. 28). A construção de uma organização escolar, e não apenas curricular, que atenda às especificidades da vida no campo, retirando do próprio meio os subsídios para o desenvolvimento dos trabalhos práticos e manuais contribui para ilustrar um modo particular de apropriação e implementação dos ideários escolanovistas no Brasil que, além de tudo, não secundariza a função dos conhecimentos científicos para a formação dos/as futuros/as professores/as.

Essa sintese operada por Antipoff, que inclui as experiências vivenciadas na Rússia, na França e na Suiça, além dos conhecimentos norteamericanos sobre a educação progressista, que ela demonstra conhecer tão bem, em seus escritos, não são trazidos e simplesmente implementados no Ginásio Normal Rural. Seus princípios e as práticas propostas são coerentes com os preceitos de respeito às especificidades individuais/locais e o fornecimento de elementos essenciais para a vida coletiva. É nesse sentido que interpretamos seu olhar sobre a função civilizadora da escola e do/a professor/a, capazes de transformar sujeitos e elevá-los a "formas superiores de pensamento e de sentimento" e de hábitos. A educação escolar é capaz de elevar o nível econômico e cultural de uma sociedade, e essas são, em suas palavras, condições mínimas para fomentar atitudes cooperativas e democráticas.

\section{Referências}

ANDRADE, Therezinha. 0 quê os diários revelam: práticas de formação de professoras para a escola rural, Curso Normal Regional Sandoval Soares de Azevedo - Ibirité, Minas Gerais, 1956-1959. Belo Horizonte: PUC-MG, 2006. 152 f. Dissertação (Mestrado em Educação) - Pontifícia Universidade Católica de Minas Gerais, Belo Horizonte, 2006.

ANTIPOFF, Helena. A Fazenda do Rosário como experiência social e pedagógica no meio rural. [1953]. In: CAMPOS, Regina H. F. (Org.). Helena Antipoff: textos escolhidos. 1. ed. São Paulo: Casa do Psicólogo, 2002. p. 277-278.

ANTIPOFF, Helena. A função social da assistência às crianças excepcionais. [1946]. In: CAMPOS, Regina H. F. (Org.). Helena Antipoff: textos escolhidos. 1. ed. São Paulo: Casa do Psicólogo, 2002. p. 247-251.

ANTIPOFF, Helena. A respeito do $4^{\circ}$ curso para professores rurais. [1953]. In: Centro de Documentação e Pesquisa Helena Antipoff (Org.). Coletânea das obras escritas de Helena Antipoff: educação rural. v. 4. 1. ed. Belo Horizonte: Imprensa Oficial, 1992. p. 95-97.

ANTIPOFF, Helena. As duas atitudes. [1947]. In: CAMPOS, Regina H. F. (Org.). Helena Antipoff: textos escolhidos. 1. ed. São Paulo: Casa do Psicólogo, 2002. p. 177-188.

ANTIPOFF, Helena. Aula Inaugural do VI curso de treinamento de educadores de base da CNER [1957]. In: CAMPOS, Regina H. F. (Org.). Helena Antipoff: textos escolhidos. 1. ed. São Paulo: Casa do Psicólogo, 2002. p. 271-275.

ANTIPOFF, Helena. Caríssimas diplomandas da primeira turma do curso normal regional Sandoval Soares de Azevedo [1953]. In: Centro de Documentação e Pesquisa Helena Antipoff (Org.). Coletânea das obras escritas de Helena Antipoff: educação rural. v. 4. 1. ed. Belo Horizonte: Imprensa Oficial, 1992. p. 99-102. 
ANTIPOFF, Helena. Educação dos excepcionais. [1955]. In: CAMPOS, Regina H. F. (Org.). Helena Antipoff: textos escolhidos. 1. ed. São Paulo: Casa do Psicólogo, 2002. p. 253-256.

ANTIPOFF, Helena. Educação dos excepcionais e sua integração na comunidade rural. [1966]. In: CAMPOS, Regina H. F. (Org.). Helena Antipoff: textos escolhidos. 1. ed. São Paulo: Casa do Psicólogo, 2002. p. 285-291.

ANTIPOFF, Helena. Granja escolar. [1962]. In: Centro de Documentação e Pesquisa Helena Antipoff (Org.) Coletânea das obras escritas de Helena Antipoff: educação rural. v. 4. 1. ed. Belo Horizonte: Imprensa Oficial, 1992. p. 141-152.

ANTIPOFF, Daniel. Helena Antipoff: sua vida, sua obra. 1. ed. Rio de Janeiro: José Olympio, 1975. 198 p.

ANTIPOFF, Helena. 0 diário do curso rural está melhorando... [1948]. In: Centro de Documentação e Pesquisa Helena Antipoff (Org.). Coletânea das obras escritas de Helena Antipoff: educação rural. v. 4. 1. ed. Belo Horizonte: Imprensa Oficial, 1992. p. 47-48.

ANTIPOFF, Helena. 0 educador em face da criança. [1939]. In: CAMPOS, Regina H. F. (Org.). Helena Antipoff: textos escolhidos. 1. ed. São Paulo: Casa do Psicólogo, 2002. p. 215-219.

ANTIPOFF, Helena. 0 problema do bem-dotado no meio-rural. [1971]. In: CAMPOS, Regina H. F. (Org.). Helena Antipoff: textos escolhidos. 1. ed. São Paulo: Casa do Psicólogo, 2002. p. 257-266.

ANTIPOFF, Helena. Orientação para o desenvolvimento das atividades pedagógicas no Curso Normal Regional da Fazenda do Rosário. [1949]. In: Centro de Documentação e Pesquisa Helena Antipoff (Org.). Coletânea das obras escritas de Helena Antipoff: educação rural. v. 4. 1. ed. Belo Horizonte: Imprensa Oficial, 1992. p. 65-69.

ANTIPOFF, Helena. Palavras de paraninfa da quarta turma de regentes de classes formadas pelo Curso Normal Regional "Sandoval Soares de Azevedo", na Fazenda do Rosário, Professora Helena Antipoff. [1958]. In: Centro de Documentação e Pesquisa Helena Antipoff (Org.). Coletânea das obras escritas de Helena Antipoff: educação rural. v. 4. 1. ed. Belo Horizonte: Imprensa Oficial, 1992. p. 121-127.

ARAÚJO, Arlete. Excursão ao São Francisco. Juventude Ruralista, Ibirité, p. 4, 19 ago. 1952.

BRASIL. Instituto Brasileiro de Geografia e Estatística. Enciclopédia dos municípios brasileiros. Planejamento e orientação de Jurandyr Pires Ferreira. Rio de Janeiro: IBGE, 1959. v. 24 e 25.

CAMPOS, Regina H. F.; ASSIS, Raquel M.; LOURENCCO, Erika. Lourenço Filho, a Escola Nova e a psicologia no Brasil. In: LOURENÇO FILHO, Manuel Bergström. Introdução ao estudo da Escola Nova. 14. ed. Rio de Janeiro: Conselho Federal de Psicologia: Eduerj, 2002. p. 14-53.

CDPHA. Centro de Documentação e Pesquisa Helena Antipoff (Org.). Coletânea das obras escritas de Helena Antipoff: educação rural. v. 4. 1. ed. Belo Horizonte: Imprensa Oficial, 1992.

CHARTIER, Anne-Marie. Um dispositivo sem autor: cadernos e fichários na escola primária. Revista Brasileira de História da Educação, Campinas, n. 3, p. 9-26, jan./jun. 2002.

CLAPARĖDE, Édouard. Psychologie de l'enfant et pédagogie expérimentale. 11. ed. Genève: Librairie Kundig, 1926.

COELHO, Cláudia M. T. Viver no campo e a educação: experiências escolares de jovens em uma escola família agrícola. Belo Horizonte: UFMG, 2009. 203 f. Dissertação (Mestrado em Educação) - Faculdade de Educação da Universidade Federal de Minas Gerais, Belo Horizonte, 2009.

DIÁRIO. Fundação Helena Antipoff. Ibirité, MG; Centro de Documentação e Pesquisa Helena Antipoff. Belo Horizonte, MG. 02 de março a 02 de maio de 1950.

DIÁRIO. Fundação Helena Antipoff. Ibirité, MG; Centro de Documentação e Pesquisa Helena Antipoff. Belo Horizonte, MG. 07 de março a 03 de maio de 1955.

DIÁRIO. Fundação Helena Antipoff. Ibirité, MG; Centro de Documentação e Pesquisa Helena Antipoff. Belo Horizonte, MG. 07 de março a 03 de maio de 1960.

DIÁRIO. Fundação Helena Antipoff. Ibirité, MG; Centro de Documentação e Pesquisa Helena Antipoff. Belo Horizonte, MG. 22 de março a 03 de maio de 1965.

DIÁRIO. Fundação Helena Antipoff. Ibirité, MG; Centro de Documentação e Pesquisa Helena Antipoff. Belo Horizonte, MG. 17 de maio a 11 de junho de 1970.

DIÁRIO. Fundação Helena Antipoff. Ibirité, MG; Centro de Documentação e Pesquisa Helena Antipoff. Belo Horizonte, MG. 13 de 
agosto a 13 de setembro de 1974.

GVIRTZ, Silvina; LARRONDO, Marina. Os cadernos de classe como fonte primária de pesquisa: alcances e limites teóricos e metodológicos para sua abordagem. In: MIGNOT, Ana ChrystinaV. Cadernos à vista: escola, memória e cultura escrita. 1. ed. Rio de Janeiro: Eduerj, 2008. p. 33-46.

HÉBRARD, Jean. Por uma bibliografia material das escritas ordinárias: o espaço gráfico do caderno escolar (França - Séculos XIX e XX). Revista Brasileira de História da Educação, Maringá, v. 1, n. 1, p. 115-141, jan./jun. 2001.

MALHEIROS, Catarina S. Escola, saberes e cotidiano no meio rural: um estudo sobre os(as) jovens do Sertão da Bahia. Brasília, DF, 2009. 167 f. Dissertação (Mestrado em Educação) - Faculdade de Educação da Universidade de Brasília (UnB). Brasília, DF, 2009.

MELLO, João M. C.; NOVAIS, Fernando A. Capitalismo tardio e sociabilidade moderna. In: NOVAIS, Fernando A.; SCHWARCZ, Lilia Moritz. História da vida privada no Brasil. 1. ed. v. 4. São Paulo: Companhia das Letras, 1998. p. 559-658.

MINAS GERAIS. Lei n² 291, 24 de novembro de 1948. Cria dois estabelecimentos de ensino normal. Diário Oficial do Estado, Belo Horizonte, 23 nov. 1948.

MINAS GERAIS. Lei n 842, 26 de dezembro de 1951. Dispõe sobre os Cursos Normais Regionais criados pela Lei n 291. Diário Oficial do Estado, Belo Horizonte, 26 dez. 1948.

MUSIAL, Gilvanice B. A emergência da escola rural em Minas Gerais (1892-1899): quando a distinção possibilita a exclusão, 2011. 258 f. Tese (Doutorado em Educação) - Faculdade de Educação, Universidade Federal de Minas Gerais (UFMG), Belo Horizonte, 2011.

PARRAT-DAYAN, Silvia; TRYPHON, Anastasia (Org.). Jean Piaget: sobre a pedagogia. 1. ed. São Paulo: Casa do Psicólogo, 1998. p. 7-23.

PINCER, Valeska de M. A formação de professores nos cursos de treinamento e aperfeiçoamento do Instituto Superior de Educação Rural - ISER: Fazenda do Rosário: 1955-1970. 2008. 134 f. Dissertação (Mestrado em Educação) - Pontifícia Universidade Católica de Minas Gerais (PUC), Belo Horizonte, 2008.

PINHO, Larissa A. Educação e saúde nos cursos de aperfeiçoamento para professores rurais: Fazenda do Rosário (Minas Gerais, 1947-1956). 2009. 155 f. Dissertação (Mestrado em Educação) - Faculdade de Educação da Universidade Federal de Minhas Gerais (UFMG), Belo Horizonte, 2009.

PINTO, Helder de M. A Escola Normal Regional D. Joaquim Silvério de Souza de Diamantina e a formação de professores para o meio rural mineiro: 1950-1970. 2007. 199 f. Dissertação (Mestrado em Educação) - Pontifícia Universidade Católica de Minas Gerais (PUC), Belo Horizonte, 2007.

SAVIANI, Demerval. História das idéias pedagógicas no Brasil. 1. ed. Campinas: Autores Associados, 2007. 474 p.

VALDEMARIN, Vera T. Método intuitivo: os sentidos como janelas e portas que se abrem para um mundo interpretado. In: SOUZA, Rosa F.; VALDEMARIN, Vera T.; ALMEIDA, Jane S. de. 0 legado educacional do século XIX. 1. ed. Araraquara: Unesp, 1998. p. 63-106.

VIÑAO, Antonio. Os cadernos escolares como fonte histórica: aspectos metodológicos e historiográficos. In: MIGNOT, Ana Chrystina V. Cadernos à vista: escola, memória e cultura escrita. 1. ed. Rio de Janeiro: Eduerj, 2008. p. 15-33.

Recebido em: 14.04.2014

Aprovado em: 14.04.2015

Mônica Yumi Jinzenji é professora adjunta do Departamento de Ciências Aplicadas à Educação (DECAE) da Faculdade de Educação da Universidade Federal de Minas Gerais (UFMG).

Iza Rodrigues da Luz é professora adjunta do Departamento de Ciências Aplicadas à Educação (DECAE) da Faculdade de Educação da Universidade Federal de Minas Gerais (UFMG).

Regina Helena de Freitas Campos é professora titular do Departamento de Ciências Aplicadas à Educação (DECAE) da Faculdade de Educação da Universidade Federal de Minas Gerais (UFMG). 
SEÇÃO: ERRATA

Errata: http://dx.doi.org/10.1590/s1517-9702202046133535E

No artigo "Escrita e leitura de diários na formação de professoras para escolas rurais em Minas Gerais (1948-1974)" DOI: https://doi.org/10.1590/s1517-97022016133535 publicado em Educação e Pesquisa, v. 43, n. 03, e217376 p.863-878, jul./set., 2017.

Na página 876.

Onde se lê:

Referências

ANTIPOFF, Daniel. A Fazenda do Rosário como experiência social e pedagógica no meio rural. [1953]. In: CAMPOS, Regina H. F. (Org.). Helena Antipoff: textos escolhidos. 1. ed. São Paulo: Casa do Psicólogo, 2002. p. 277-278.

ANTIPOFF, Daniel. A função social da assistência às crianças excepcionais. [1946]. In: CAMPOS, Regina H. F. (Org.). Helena Antipoff: textos escolhidos. 1. ed. São Paulo: Casa do Psicólogo, 2002. p. 247-251.

ANTIPOFF, Daniel. A respeito do $4^{\circ}$ curso para professores rurais. [1953]. In: Centro de Documentação e Pesquisa Helena Antipoff (Org.). Coletânea das obras escritas de Helena Antipoff: educação rural. v. 4. 1. ed. Belo Horizonte: Imprensa Oficial, 1992. p. 95-97.

ANTIPOFF, Daniel. As duas atitudes. [1947]. In: CAMPOS, Regina H. F. (Org.). Helena Antipoff: textos escolhidos. 1. ed. São Paulo: Casa do Psicólogo, 2002. p. 177188.

ANTIPOFF, Daniel. Aula Inaugural do VI curso de treinamento de educadores de base da CNER [1957]. In: CAMPOS, Regina H. F. (Org.). Helena Antipoff: textos escolhidos. 1. ed. São Paulo: Casa do Psicólogo, 2002. p. 271-275.

ANTIPOFF, Daniel. Caríssimas diplomandas da primeira turma do curso normal regional Sandoval Soares de Azevedo [1953]. In: Centro de Documentação e Pesquisa Helena Antipoff (Org.). Coletânea das obras escritas de Helena Antipoff: educação rural. v. 4. 1. ed. Belo Horizonte: Imprensa Oficial, 1992. p. 99-102.

Leia-se:

ANTIPOFF, Helena. A Fazenda do Rosário como experiência social e pedagógica no meio rural. [1953]. In: CAMPOS, Regina H. F. (Org.). Helena Antipoff: textos escolhidos. 1. ed. São Paulo: Casa do Psicólogo, 2002. p. 277-278.

ANTIPOFF, Helena. A função social da assistência às crianças excepcionais. [1946]. In: CAMPOS, Regina H. F. (Org.). Helena Antipoff: textos escolhidos. 1. ed. São Paulo: Casa do Psicólogo, 2002. p. 247-251. 
ANTIPOFF, Helena. A respeito do $4^{\circ}$ curso para professores rurais. [1953]. In: Centro de Documentação e Pesquisa Helena Antipoff (Org.). Coletânea das obras escritas de Helena Antipoff: educação rural. v. 4. 1. ed. Belo Horizonte: Imprensa Oficial, 1992. p. 9597.

ANTIPOFF, Helena. As duas atitudes. [1947]. In: CAMPOS, Regina H. F. (Org.). Helena Antipoff: textos escolhidos. 1. ed. São Paulo: Casa do Psicólogo, 2002. p. 177 188.

ANTIPOFF, Helena. Aula Inaugural do VI curso de treinamento de educadores de base da CNER [1957]. In: CAMPOS, Regina H. F. (Org.). Helena Antipoff: textos escolhidos. 1. ed. São Paulo: Casa do Psicólogo, 2002. p. 271-275.

ANTIPOFF, Helena. Caríssimas diplomandas da primeira turma do curso normal regional Sandoval Soares de Azevedo [1953]. In: Centro de Documentação e Pesquisa Helena Antipoff (Org.). Coletânea das obras escritas de Helena Antipoff: educação rural. v. 4. 1. ed. Belo Horizonte: Imprensa Oficial, 1992. p. 99-102.

Na página 877.

Onde se lê:

Referências

ANTIPOFF, Daniel. Educação dos excepcionais. [1955]. In: CAMPOS, Regina H. F. (Org.). Helena Antipoff: textos escolhidos. 1. ed. São Paulo: Casa do Psicólogo, 2002. p. 253-256.

ANTIPOFF, Daniel. Educação dos excepcionais e sua integração na comunidade rural. [1966]. In: CAMPOS, Regina H. F. (Org.). Helena Antipoff: textos escolhidos. 1. ed. São Paulo: Casa do Psicólogo, 2002. p. 285-291.

ANTIPOFF, Daniel. Granja escolar. [1962]. In: Centro de Documentação e Pesquisa Helena Antipoff (Org.) Coletânea das obras escritas de Helena Antipoff: educação rural. v. 4. 1. ed. Belo Horizonte: Imprensa Oficial, 1992. p. 141-152.

ANTIPOFF, Daniel. O diário do curso rural está melhorando... [1948]. In: Centro de Documentação e Pesquisa Helena Antipoff (Org.). Coletânea das obras escritas de Helena Antipoff: educação rural. v. 4. 1. ed. Belo Horizonte: Imprensa Oficial, 1992. p. 47-48.

ANTIPOFF, Daniel. O educador em face da criança. [1939]. In: CAMPOS, Regina H. F. (Org.). Helena Antipoff: textos escolhidos. 1. ed. São Paulo: Casa do Psicólogo, 2002. p. 215-219. 
ANTIPOFF, Daniel. O problema do bem-dotado no meio-rural. [1971]. In: CAMPOS, Regina H. F. (Org.). Helena Antipoff: textos escolhidos. 1. ed. São Paulo: Casa do Psicólogo, 2002. p. 257-266.

ANTIPOFF, Daniel. Orientação para o desenvolvimento das atividades pedagógicas no Curso Normal Regional da Fazenda do Rosário. [1949]. In: Centro de Documentação e Pesquisa Helena Antipoff (Org.). Coletânea das obras escritas de Helena Antipoff: educação rural. v. 4. 1. ed. Belo Horizonte: Imprensa Oficial, 1992. p. 65-69.

ANTIPOFF, Daniel. Palavras de paraninfa da quarta turma de regentes de classes formadas pelo Curso Normal Regional "Sandoval Soares de Azevedo", na Fazenda do Rosário, Professora Helena Antipoff. [1958]. In: Centro de Documentação e Pesquisa Helena Antipoff (Org.). Coletânea das obras escritas de Helena Antipoff: educação rural. v. 4. 1. ed. Belo Horizonte: Imprensa Oficial, 1992. p. 121-127.

Leia-se:

ANTIPOFF, Helena. Educação dos excepcionais. [1955]. In: CAMPOS, Regina H. F. (Org.). Helena Antipoff: textos escolhidos. 1. ed. São Paulo: Casa do Psicólogo, 2002. p. 253-256.

ANTIPOFF, Helena. Educação dos excepcionais e sua integração na comunidade rural. [1966]. In: CAMPOS, Regina H. F. (Org.). Helena Antipoff: textos escolhidos. 1. ed. São Paulo: Casa do Psicólogo, 2002. p. 285-291.

ANTIPOFF, Helena. Granja escolar. [1962]. In: Centro de Documentação e Pesquisa Helena Antipoff (Org.) Coletânea das obras escritas de Helena Antipoff: educação rural. v. 4. 1. ed. Belo Horizonte: Imprensa Oficial, 1992. p. 141-152.

ANTIPOFF, Helena. O diário do curso rural está melhorando... [1948]. In: Centro de Documentação e Pesquisa Helena Antipoff (Org.). Coletânea das obras escritas de Helena Antipoff: educação rural. v. 4. 1. ed. Belo Horizonte: Imprensa Oficial, 1992. p. 47-48.

ANTIPOFF, Helena. O educador em face da criança. [1939]. In: CAMPOS, Regina H. F. (Org.). Helena Antipoff: textos escolhidos. 1. ed. São Paulo: Casa do Psicólogo, 2002. p. 215-219.

ANTIPOFF, Helena. O problema do bem-dotado no meio-rural. [1971]. In: CAMPOS, Regina H. F. (Org.). Helena Antipoff: textos escolhidos. 1. ed. São Paulo: Casa do Psicólogo, 2002. p. 257-266.

ANTIPOFF, Helena. Orientação para o desenvolvimento das atividades pedagógicas no Curso Normal Regional da Fazenda do Rosário. [1949]. In: Centro de Documentação e Pesquisa Helena Antipoff (Org.). Coletânea das obras escritas de Helena Antipoff: educação rural. v. 4. 1. ed. Belo Horizonte: Imprensa Oficial, 1992. p. 65-69.

ANTIPOFF, Helena. Palavras de paraninfa da quarta turma de regentes de classes formadas pelo Curso Normal Regional "Sandoval Soares de Azevedo", na Fazenda do 
Rosário, Professora Helena Antipoff. [1958]. In: Centro de Documentação e Pesquisa Helena Antipoff (Org.). Coletânea das obras escritas de Helena Antipoff: educação rural. v. 4. 1. ed. Belo Horizonte: Imprensa Oficial, 1992. p. 121-127.

Educ. Pesqui., São Paulo, v. 46, e133535E, 2020.

DOI: http://dx.doi.org/10.1590/s1678-4634202046133535E 